\title{
LETTER
}

\section{Transformation process of amorphous magnesium carbonate in aqueous solution}

\author{
Jun-ya TANAKA*, Jun KawANo**, Takaya NAGAI ${ }^{* *}$ and Henry TenG ${ }^{* * *}$ \\ ${ }^{*}$ Department of Natural History Sciences, Graduate School of Science, Hokkaido University, Sapporo 060-0810, Japan \\ ${ }^{* *}$ Department of Earth and Planetary Sciences, Faculty of Science, Hokkaido University, Sapporo 060-0810, Japan \\ *** Institute of Surface-Earth System Science, Tianjin University, Tianjin 300072, P.R. China
}

\begin{abstract}
Amorphous magnesium carbonate (AMC) is an important phase in the early formation stage of magnesium carbonate. In this study, precipitation experiments were conducted to clarify the formation and transformation process of AMC in aqueous solution. Fine AMC particles precipitated, immediately after mixing of $\mathrm{Na}_{2} \mathrm{CO}_{3}$ and $\mathrm{MgCl}_{2}$ solutions. Chemical composition of the $\mathrm{AMC}$ was determined to be approximately $\mathrm{MgCO}_{3} \cdot 2 \mathrm{H}_{2} \mathrm{O}$ although two hydration states were expected to exist for AMCs. Subsequently, the AMC transformed in aqueous solutions into needle-like crystals of nesquehonite $\left(\mathrm{MgCO}_{3} \cdot 3 \mathrm{H}_{2} \mathrm{O}\right)$, eventually to tiny polycrystalline particles of dypingite $\left[\mathrm{Mg}_{5}\left(\mathrm{CO}_{3}\right)_{4}(\mathrm{OH})_{2} \cdot 5 \mathrm{H}_{2} \mathrm{O}\right]$ via a solvent-mediated processes.
\end{abstract}

Keywords: Amorphous, Magnesium carbonate, Hydration

\section{INTRODUCTION}

Crystal formation of carbonate minerals from aqueous solution via amorphous precursor is often reported (Ogino et al., 1987; Kawano et al., 2002) and has recently attracted more research interest in various fields such as biomineralization (Addadi et al., 2003; Von Euw et al., 2017) and the design of new materials (Oaki et al., 2008; Matsunuma et al., 2014). Although a large number of studies have been performed, this crystallization mechanism is poorly understood. To probe this problem, we examined the model system of $\mathrm{MgO}-\mathrm{CO}_{2}-\mathrm{H}_{2} \mathrm{O}$. In this system, magnesite $\left(\mathrm{MgCO}_{3}\right)$ is the most stable phase. Modern magnesite is considered to have precipitated under atmospheric pressure and temperature in nature, however it cannot be synthesized from aqueous solutions at ambient conditions (so-called 'the magnesite problem'; Deelman, 2011). Instead, various hydrated magnesium carbonates such as nesquehonite $\left(\mathrm{MgCO}_{3} \cdot 3 \mathrm{H}_{2} \mathrm{O}\right)$, hydromagnesite $\left[\mathrm{Mg}_{5}\right.$ $\left.\left(\mathrm{CO}_{3}\right)_{4}(\mathrm{OH})_{2} \cdot 4 \mathrm{H}_{2} \mathrm{O}\right]$, and dypingite $\left[\mathrm{Mg}_{5}\left(\mathrm{CO}_{3}\right)_{4}(\mathrm{OH})_{2}\right.$. $5 \mathrm{H}_{2} \mathrm{O}$ ] have been reported to precipitate from solution in the laboratory (Canterford and Tsambourakis, 1984; Hänchen et al., 2008). However, little is known concern-

doi:10.2465/jmps.181119b

J. Tanaka, j-tanaka@sci.hokudai.ac.jp Corresponding author

J. Kawano, j-kawano@sci.hokudai.ac.jp ing the relation between the properties of AMC and the final crystalline magnesium carbonate hydrates.

Recently amorphous magnesium carbonate (AMC) was reported to precipitate from supersaturated solution (Radha et al., 2012). Montes-Hernandez and Renard (2016) suggested that AMC transformed into nesquehonite, eventually dypingite while Fukushi et al. (2017) reported hydromagnesite precipitated from AMC in the presence of monohydrocalcite $\left(\mathrm{CaCO}_{3} \cdot \mathrm{H}_{2} \mathrm{O}\right)$ in the aqueous system of $\mathrm{CaO}-\mathrm{MgO}-\mathrm{CO}_{2}$. The detail transformation mechanism, for example, change of hydration state or molecular behavior during this process, is still unclear. AMC may play a significant role in magnesium carbonate formation, thus understanding the hydration/dehydration process of AMC may lead to revealing the magnesite formation. The goal of this study is to explore this issue by examining the transformation process of AMC in aqueous solution.

\section{EXPERIMENTAL PROCEDURE}

\section{Precipitation experiment}

Precipitation experiments were conducted by mixing of $25 \mathrm{ml}$ of $0.2 \mathrm{M} \mathrm{Na}_{2} \mathrm{CO}_{3}$ and $25 \mathrm{ml}$ of $0.2 \mathrm{M} \mathrm{MgCl}_{2}$ solutions in a PTFE (polytetrafluoroethylene) beaker in a 
closed system sealed with a rubber stopper. After rapid mixing, the solution was stirred magnetically in the thermostat bath at $15{ }^{\circ} \mathrm{C}$. Solution $\mathrm{pH}$ was monitored by means of $\mathrm{pH}$ electrode (Metrohm No. 6.0258.100) calibrated with standard buffers ( $\mathrm{pH} 7.00$ and 9.00). In addition, the solutions and precipitates were monitored by an optical microscopy every $1000 \mathrm{~s}$ to $10000 \mathrm{~s}$ and every $100000 \mathrm{~s}$ to $1800000 \mathrm{~s}$ throughout the experiments.

\section{Sample analysis}

For phase identification, precipitates were collected and filtrated through a $0.2 \mu \mathrm{m}$ membrane filter. After drying in a desiccator evacuated with a diaphragm pump $(\sim 0.1$ $\mathrm{MPa}$ ) overnight, the powder samples were harvested for additional analyses. Powder X-ray diffraction (XRD; $\mathrm{CuK \alpha}, 40 \mathrm{kV}, 30 \mathrm{~mA}$ ) pattern of the samples were acquired using MAC Science MX-Labo in the range $2 \theta=$ $2-70^{\circ}$. Transmission electron microscopy (TEM) was performed using a JEOL JEM-2010 operated at $200 \mathrm{kV}$ to obtain electron diffraction. A scanning electron microscope (SEM; JEOL JCM-500 NeoScope) was used to observe their morphologies. Infrared absorbance spectra of the powder samples were measured by a Fourier Transform Infrared (FT-IR) spectrometer (JASCO FT/IR 6100) equipped with an attenuated total reflection (ATR) stage at resolution of $2 \mathrm{~cm}^{-1}$ and accumulation of 100 scans. In addition, thermogravimetry-differential thermal analysis (TG-DTA, Rigaku Thermo plus EVO TG 8120) was performed by heating the samples on an alumina pan in flowing $\mathrm{N}_{2}$ gas $(100 \mathrm{ml} / \mathrm{min})$ with alumina powder as a standard material to determine the concentrations of $\mathrm{CO}_{2}$ and $\mathrm{H}_{2} \mathrm{O}$ constituents in the samples. The heating conditions were followed the scheme suggested by Lin et al. (2015): raising $T$ at $10{ }^{\circ} \mathrm{C} / \mathrm{min}$ to $100{ }^{\circ} \mathrm{C}$, keeping $T$ at $100{ }^{\circ} \mathrm{C}$ for 20 minutes; and raising $T$ again at $10^{\circ} \mathrm{C} / \mathrm{min}$ to $1400^{\circ} \mathrm{C}$.

\section{RESULTS AND DISCUSSION}

\section{Amorphous magnesium carbonate}

Upon quickly mixing of the pre-prepared salt solutions, a white slurry of fine precipitates was observed in a few seconds. Powder XRD pattern of the precipitates collected immediately after did not show any apparent peaks, indicating that the early formed precipitate was amorphous phase. The lack of crystallinity was further confirmed by TEM, which revealed a halo pattern under selected area electron diffraction (SAED) on the fine precipitated nano-particles (Fig. 1). The infrared absorption bands corresponding to $\mathrm{H}_{2} \mathrm{O}\left(1654\right.$ and $\left.3354 \mathrm{~cm}^{-1}\right)$ and $\mathrm{CO}_{3}$ vibration $\left(858,1098\right.$, and $\left.1456 \mathrm{~cm}^{-1}\right)$ were observed, indicat-

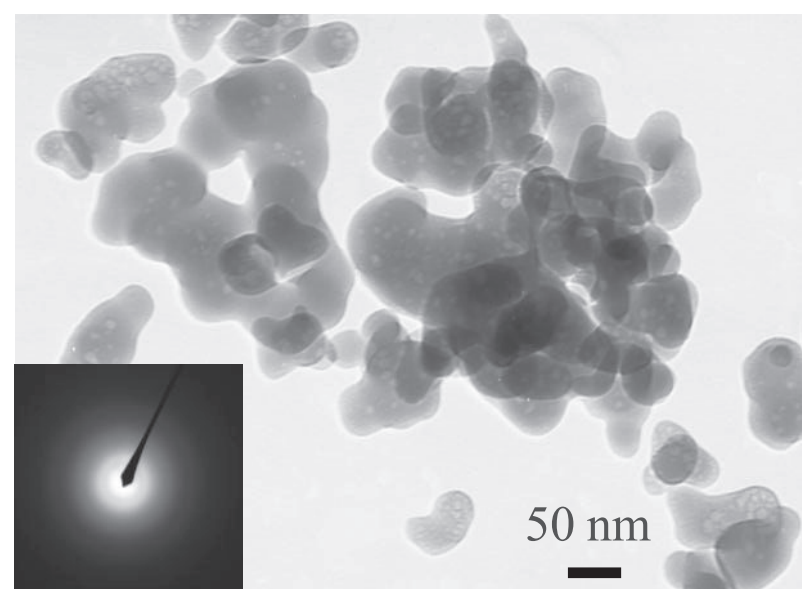

Figure 1. TEM image and electron diffraction of AMC (inset: SAED).

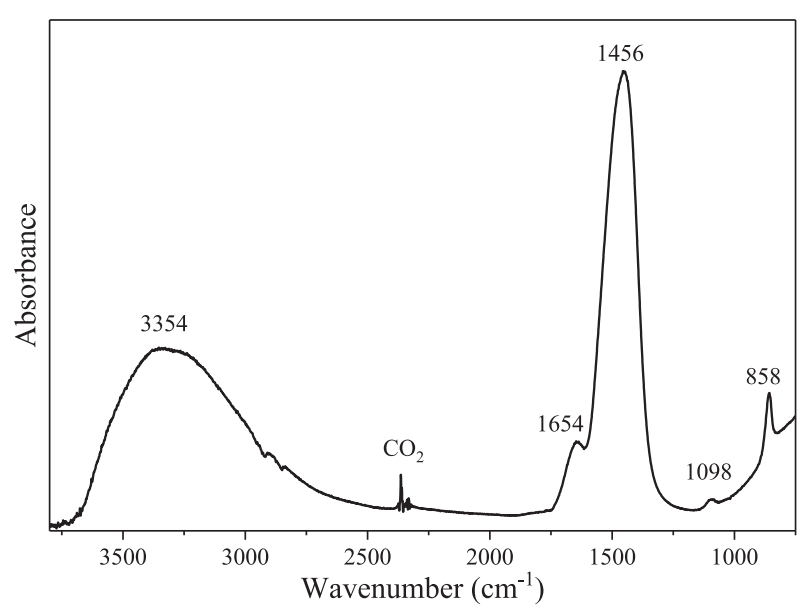

Figure 2. FT-IR spectrum of AMC.

ing that hydrous status of the precipitated AMC (Fig. 2).

TG-DTA was performed up to the temperature the powder $\mathrm{AMC}$ was decomposed into periclase $(\mathrm{MgO})$ in order to determine the composition of AMC (Fig. 3). We found that endothermic reaction of decomposition of AMC proceeded via three weight losses thought of as two dehydration $\left(<100{ }^{\circ} \mathrm{C}\right.$ and $\left.100-200{ }^{\circ} \mathrm{C}\right)$ and one decarbonation $\left(>200{ }^{\circ} \mathrm{C}\right)$ reactions. There seemed to be a few endothermic peaks in DTA profile over $500{ }^{\circ} \mathrm{C}$, tiny amount (negligible weight losses) of sodium salts. It is possible that the second weight loss was caused by the following dehydroxylation reaction: $\mathrm{Mg}(\mathrm{OH})_{2} \rightarrow \mathrm{MgO}+$ $\mathrm{H}_{2} \mathrm{O}$. However, if the present AMC has such hydroxyl groups, the charge balance of the AMC can not be maintained. Thus, the AMC should not contain $\operatorname{Mg}(\mathrm{OH})_{2}$. From this result, it was calculated that the weight losses for two dehydration reactions were 17.5 and $12.4 \mathrm{wt} \%$ and it for the decarbonation reaction was $36.4 \mathrm{wt} \%$, respectively. Thus, the chemical composition of AMC was 


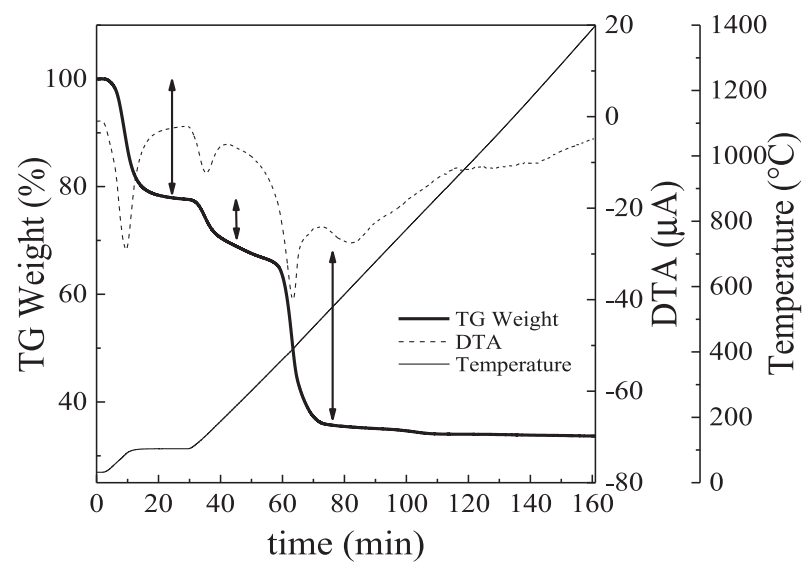

Figure 3. TG-DTA curves of AMC. TG weight, DTA, and temperature profiles were shown as the bold, dotted and fine line, respectively. Black arrows indicate three weight losses corresponding to dehydration and decarbonation reactions of AMC.

determined to be about $\mathrm{MgCO}_{3} \cdot 2 \mathrm{H}_{2} \mathrm{O}$. This AMC contained more water than $\mathrm{AMC}$ previously reported in Lin et al. (2015) $\left(\mathrm{MgCO}_{3} \cdot 0.91 \mathrm{H}_{2} \mathrm{O}\right)$ and Radha et al. (2012) $\left(\mathrm{MgCO}_{3} \cdot 1.28 \mathrm{H}_{2} \mathrm{O}\right)$. Furthermore, the detection of two weight losses below $100{ }^{\circ} \mathrm{C}$ and from 100 to $200{ }^{\circ} \mathrm{C}$ suggested the existence of two types of hydration waters, consistent with the measurement by Lin et al. (2015), corresponding to a loosely bound water stable at $T$ $<100{ }^{\circ} \mathrm{C}$ and a tightly bound water stable in the temperature range of 100 to $200{ }^{\circ} \mathrm{C}$. This concept was based on Schmidt et al. (2014), who showed the weight loss below $100{ }^{\circ} \mathrm{C}$ of amorphous calcium carbonate was due to the dehydration of not only physisorbed water but also structural water. AMC obtained in the present study thermally decomposed in the same way as Lin et al. (2015), thought to contain loosely bound water (58\%) and tightly bound water $(42 \%)$. Whether this AMC has the same structure as the one reported in previous studies remains to be investigated, however, it appears safe to conclude that AMCs may have various water contents and perhaps different hydration states.

\section{Transformation into nesquehonite}

Measured $\mathrm{pH}$ near the time of initial AMC formation was around 10 , but gradually decreased slightly to 9.95 in $3000 \mathrm{~s}$ (stage I in Fig. 4). After that, AMC began to dissolve with increasing $\mathrm{pH}$ (stage II). At the same time, well-defined needle crystals of several tens micrometers were observed under optical and SEM microscope (Fig. 5A). AMC were still existed separately, suggesting that the transformation of AMC by a solvent-mediated mechanism. XRD pattern of the precipitates indicated that the needle crystals were nesquehonite $\left(\mathrm{MgCO}_{3} \cdot 3 \mathrm{H}_{2} \mathrm{O}\right)$, one

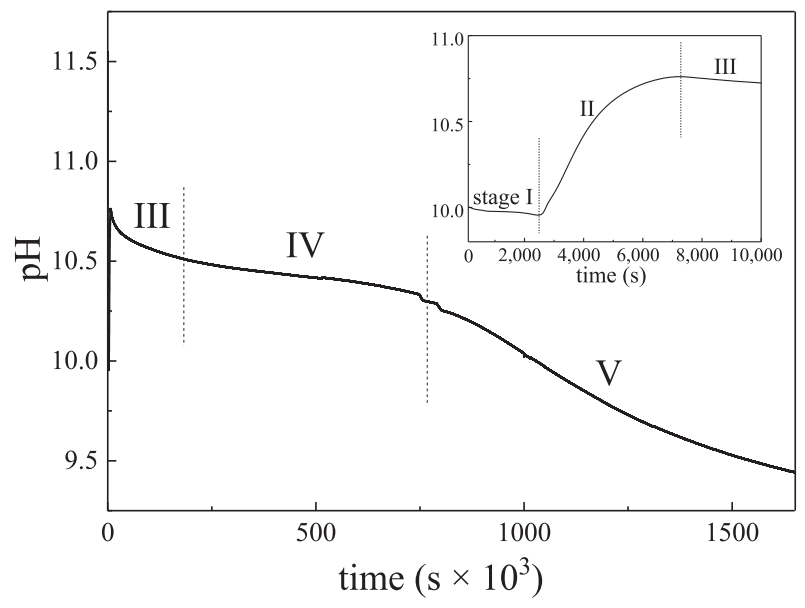

Figure 4. The change of solution $\mathrm{pH}$ with time. This $\mathrm{pH}$ change can be divided into 5 stages. The early stage of the measurement is shown in the inset.
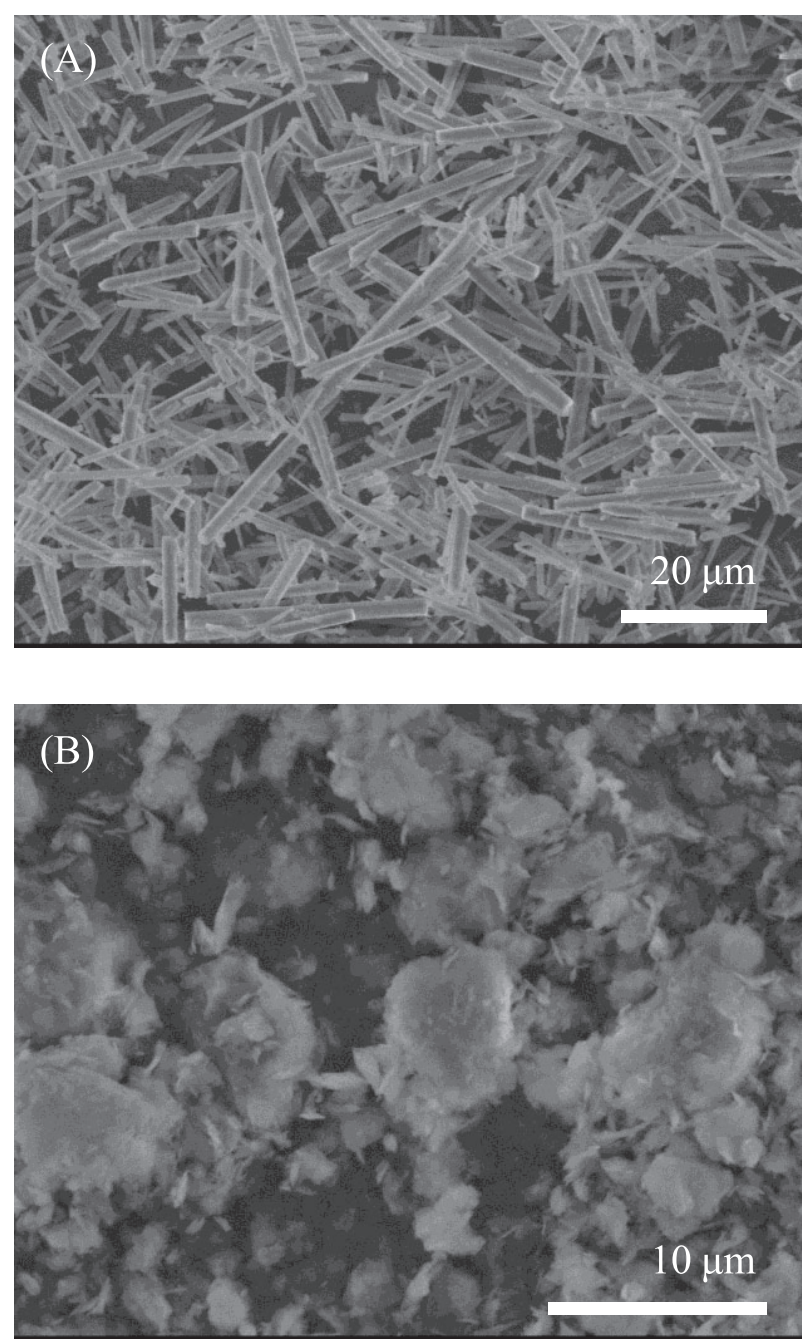

Figure 5. SEM image of precipitates (A) $5000 \mathrm{~s}$ and (B) 1800000 $\mathrm{s}$ after mixing. 
of the hydrated magnesium carbonates. Sharp XRD peaks of nesquehonite imply a good crystallinity (Fig. 6A). However, electron diffraction could not be obtained for nesquehonite because nesquehonite crystals immediately transformed into amorphous phase by electron beam damage during the TEM observation.

Nesquehonite may have started forming in stage I and the rise of $\mathrm{pH}$ in stage II may be caused by the dissolution of AMC exceeding the formation of nesquehonite, which means the following reaction could have occurred:

$$
\mathrm{MgCO}_{3} \cdot 2 \mathrm{H}_{2} \mathrm{O}+\mathrm{H}^{+} \rightarrow \mathrm{Mg}^{2+}+\mathrm{HCO}_{3}^{-}+2 \mathrm{H}_{2} \mathrm{O} .
$$

When the formation reaction of nequehonite became predominant, the slope of $\mathrm{pH}$ change turned from positive to negative at 10.8 .

\section{Transformation into dypingite}

After $240000 \mathrm{~s}$ of $\mathrm{pH}$ drop (stage III), solution $\mathrm{pH}$ was stable at around 10.4, indicating that nesquehonite was in quasi-equilibrium with solution (stage IV in Fig. 4). $\mathrm{pH}$ started decreasing again at $750000 \mathrm{~s}$ (stage V), indicating that a less soluble phase started precipitating, following the dissolution of nequehonite. It is thought that the dissolution of atmospheric $\mathrm{CO}_{2}$ does not greatly affect this $\mathrm{pH}$ change because the amount of $\mathrm{CO}_{2}$ is much smaller than carbonate ions in the closed beaker. A lot of newly formed tiny particles and shortened nesquehonite needle crystals were observed in the precipitates formed in this period as seen under optical microscope. This result indicates the solvent-mediated transformation from nesquehonite to another phase occurred. From powder XRD pattern (Fig. 6B), the new phase was identified as dypingite $\left[\mathrm{Mg}_{5}\left(\mathrm{CO}_{3}\right)_{4}(\mathrm{OH})_{2} \cdot 5 \mathrm{H}_{2} \mathrm{O}\right]$, another phase of hydrated magnesium carbonates. To the best of our knowledge, there has been no reports about detail crystal structure of dypingite but is believed to be a similar structure of hydromagnesite $\left[\mathrm{Mg}_{5}\left(\mathrm{CO}_{3}\right)_{4}(\mathrm{OH})_{2} \cdot 4 \mathrm{H}_{2} \mathrm{O}\right]$ (Hopkinson et al., 2012). Raade (1970) pointed out that these two phases have similar XRD patterns, however dypingite has a characteristic peak at $2 \theta=8.3^{\circ}$, so can be distinguished from hydromagnesite. Solubility of dypingite has not been reported either, however the structural similarity to hydromagnesite suggests that it is also similar to that of hydromagnesite [the solubility product of hydromagnesite, $\mathrm{K}_{\text {sp-hydromagnesite }}=10^{-36.77}$, for the following equilibrium: $\mathrm{Mg}_{5}\left(\mathrm{CO}_{3}\right)_{4}(\mathrm{OH})_{2} \cdot 4 \mathrm{H}_{2} \mathrm{O} \rightarrow 5 \mathrm{Mg}^{2+}+4 \mathrm{CO}_{3}^{2-}+2 \mathrm{OH}^{-}+$ $4 \mathrm{H}_{2} \mathrm{O}$, calculated using Königsberger et al., 1999] which is lower than nesquehonite $\left(\mathrm{K}_{\text {sp-nesquehonite }}=10^{-5.31}\right.$, in the form of $\mathrm{MgCO}_{3} \cdot 3 \mathrm{H}_{2} \mathrm{O} \rightarrow \mathrm{Mg}^{2+}+\mathrm{CO}_{3}^{2-}+3 \mathrm{H}_{2} \mathrm{O}$, calcu-
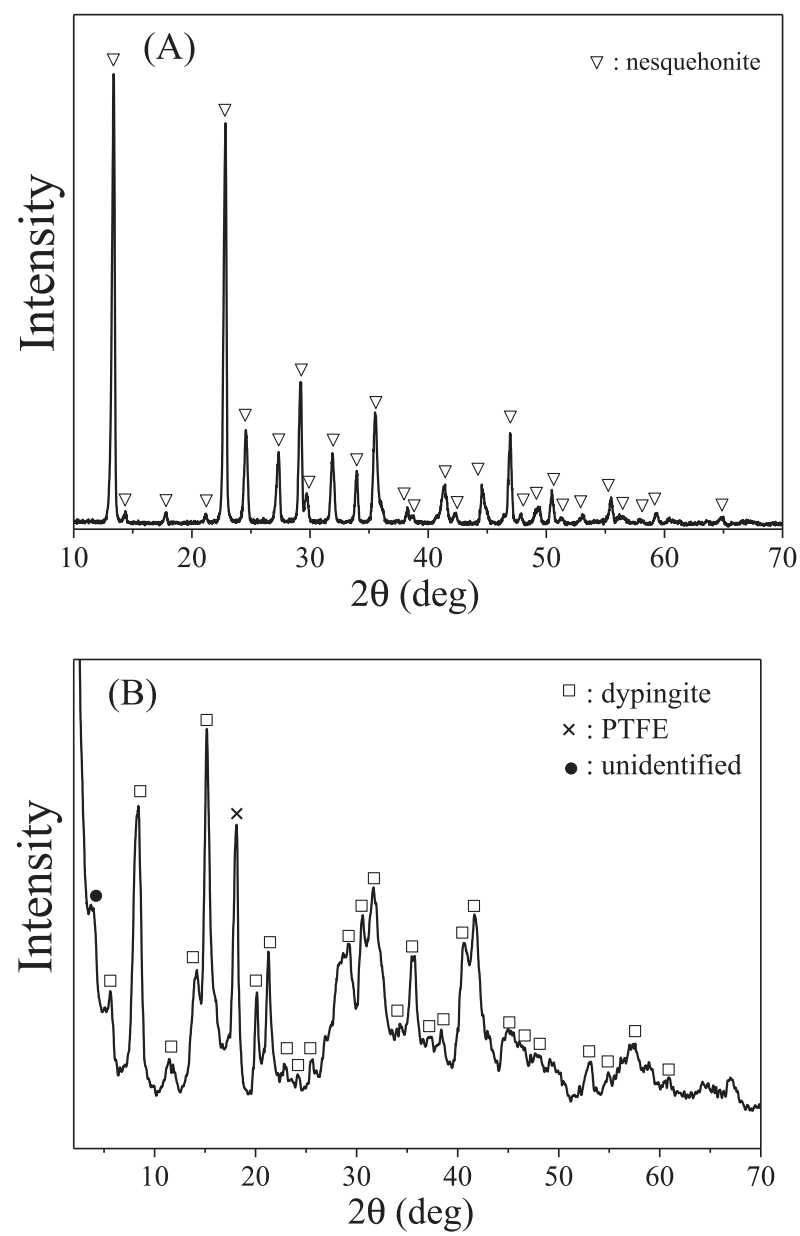

Figure 6. Powder XRD patterns of precipitates (A) $5000 \mathrm{~s}$ and (B) $1800000 \mathrm{~s}$ after mixing. (A) All peaks are agreement with the pattern of nesquehonite (Stephan and MacGillavry, 1972). (B) Almost all of peaks correspond to X-ray powder data reported by Raade (1970) in the range $2 \theta=5.8-60.9^{\circ}$.

lated using Königsberger et al., 1999). Broad XRD peaks, SEM images and SAED of the powder sample indicated that the precipitated dypingite was fine polycrystalline particles with low crystallinity (Figs. 5B and 6B). It should be noted that, in this transformation, crystals with well developed morphology and high crystallinity transformed into irregular shaped tiny crystals with low crystallinity increasing the surface energy, possibly affected by the stabilities of nesquehonite and dypingite. The reason for this transformation is unknown, however, the driving force for this transformation could be due to the difference of the $\mathrm{K}_{\mathrm{sp}}$ between these two phases. The solution in stage IV would be saturated with respect to nesquehonite but supersaturated with dypingite.

To conclude, we showed in this study the formation of AMC immediately after mixing of $0.2 \mathrm{M} \mathrm{MgCl}_{2}$ and $\mathrm{Na}_{2} \mathrm{CO}_{3}$ solutions. This AMC had an approximated chemical formula $\mathrm{MgCO}_{3} \cdot 2 \mathrm{H}_{2} \mathrm{O}$ and contained two types 
(loosely and tightly bounded) of waters. It transformed into well-developed needle crystals of nesquehonite $\left(\mathrm{MgCO}_{3} \cdot 3 \mathrm{H}_{2} \mathrm{O}\right)$ during the mixing solution in dozens of minuets; after that, nesquehonite transformed into irregular shaped tiny crystals of dypingite $\left[\mathrm{Mg}_{5}\left(\mathrm{CO}_{3}\right)_{4}(\mathrm{OH})_{2}\right.$. $\left.5 \mathrm{H}_{2} \mathrm{O}\right]$. Both transformations were solvent-mediated. Considering hydration/dehydration behavior, water content increased in the former transformation, and $\mathrm{Mg}$ / $\mathrm{CO}_{3}$ ratio of the solid phases deviated from 1 in the latter. Both processes are opposite trends to the direct route for the formation of the most stable phase, magnesite, which is anhydrous and $\mathrm{Mg} / \mathrm{CO}_{3}=1$.

\section{ACKNOWLEDGMENTS}

The authors would like to express thanks to H. Kagi and H. Yurimoto for their valuable help. We would like to thank M. Kawano for editorial handling and the two anonymous reviewers for their useful comments. This work was supported by the Sasakawa Scientific Research Grant from The Japan Science Society.

\section{REFERENCES}

Addadi, L., Raz, S. and Weiner, S. (2003) Taking advantage of disorder: Amorphous calcium carbonate and its roles in biomineralization. Advanced Materials, 15, 959-970.

Canterford, J.H. and Tsambourakis, G. (1984) Some Observations on the Properties of Dypingite, $\mathrm{Mg}_{5}\left(\mathrm{CO}_{3}\right)_{4}(\mathrm{OH})_{2} \cdot 5 \mathrm{H}_{2} \mathrm{O}$, and Related Minerals. Mineralogical Magazine, 48, 437-442.

Deelman, J.C. (2011) Low-temperature formation of dolomite and magnesite. Chapter 6, Magnesite \& Huntite, 188-212. http:// www.jcdeelman.demon.nl/dolomite/bookprospectus.html

Fukushi, K., Suzuki, Y., Kawano, J., Ohno, T., Ogawa, M., Yaji, T. and Takahashi, Y. (2017) Speciation of magnesium in monohydrocalcite: XANES, ab initio and geochemical modeling. Geochimica et Cosmochimica Acta, 213, 457-474.

Hänchen, M., Prigiobbe, V., Baciocchi, R. and Mazzotti, M. (2008) Precipitation in the $\mathrm{Mg}$-carbonate system-effects of temperature and $\mathrm{CO}_{2}$ pressure. Chemical Engineering Science, 63, 1012-1028.

Hopkinson, L., Kristova, P., Rutt, K. and Cressey, G. (2012) Phase transitions in the system $\mathrm{MgO}-\mathrm{CO}_{2}-\mathrm{H}_{2} \mathrm{O}$ during $\mathrm{CO}_{2}$ degassing of $\mathrm{Mg}$-bearing solutions. Geochimica et Cosmochimica Acta, 76, 1-13.
Kawano, J., Shimobayashi, N., Kitamura, M., Shinoda, K. and Aikawa, N. (2002) Formation process of calcium carbonate from highly supersaturated solution. Journal of Crystal Growth, 237-239, 419-423.

Königsberger, E., Königsberger, L.-C. and Gamsjäger, H. (1999) Low-temperature thermodynamic model for the system $\mathrm{Na}_{2} \mathrm{CO}_{3}-\mathrm{MgCO}_{3}-\mathrm{CaCO}_{3}-\mathrm{H}_{2} \mathrm{O}$. Geochimica et Cosmochimica Acta, 63, 3105-3119.

Lin, C.-J., Yang, S.-Y., Huang, S.-J. and Chan, J.C.C. (2015) Structural Characterization of Mg-Stabilized Amorphous Calcium Carbonate by Mg-25 Solid-State NMR Spectroscopy. The Journal of Physical Chemistry, C 119, 7225-7233.

Matsunuma, S., Kagi, H., Komatsu, K., Maruyama, K. and Yoshino, T. (2014) Doping incompatible elements into calcite through amorphous calcium carbonate. Crystal Growth and Design, 14, 5344-5348.

Montes-Hernandez, G. and Renard, F. (2016) Time-Resolved in Situ Raman Spectroscopy of the Nucleation and Growth of Siderite, Magnesite, and Calcite and Their Precursors. Crystal Growth and Design, 16, 7218-7230.

Oaki, Y., Kajiyama, S., Nishimura, T., Imai, H. and Kato, T. (2008) Nanosegregated amorphous composites of calcium carbonate and an organic polymer. Advanced Materials, 20, 3633-3637.

Ogino, T., Suzuki, T. and Sawada, K. (1987) The formation and transformation mechanisme of calcium carbonate in water. Geochimica Et Cosmochimica Acta, 51, 2757-2767.

Raade, G. (1970) Dypingite, a new hydrous basic carbonate of magnesium, from Norway. American Mineralogist, 55, 1457-1465.

Radha, A. V, Fernandez-Martinez, A., Hu, Y., Jun, Y.-S., Waychunas, G.A. and Navrotsky, A. (2012) Energetic and structural studies of amorphous $\mathrm{Ca}_{1-\mathrm{x}} \mathrm{Mg}_{\mathrm{x}} \mathrm{CO}_{3} \cdot \mathrm{nH}_{2} \mathrm{O}(0 \leq \mathrm{x} \leq 1)$. Geochimica et Cosmochimica Acta, 90, 83-95.

Schmidt, M.P., Ilott, A.J., Phillips, B.L. and Reeder, R.J. (2014) Structural Changes upon Dehydration of Amorphous Calcium Carbonate. Crystal Growth \& Design, 14, 938-951.

Stephan, G.W. and MacGillavry, C.H. (1972) The crystal structure of nesquehonite, $\mathrm{MgCO}_{3} \cdot 3 \mathrm{H}_{2} \mathrm{O}$. Acta Crystallographica Section B, Structural Crystallography and Crystal Chemistry, 28, 1031-1033.

Von Euw, S., Zhang, Q., Manichev, V., Murali, N., Gross, J., Feldman, L.C., Gustafsson, T., Flach, C., Mendelsohn, R. and Falkowski, P.G. (2017) Biological control of aragonite formation in stony corals. Science, 356, 933-938.

Manuscript received November 19, 2018

Manuscript accepted March 4, 2019

Published online April 10, 2019

Manuscript handled by Motoharu Kawano 